\title{
Isolation and Structure of Antimicrobial Substances from Paprika Seeds
}

\author{
Mizuo YAJIMA, ${ }^{1}$ Tsutomu TAKAYANAGI, ${ }^{2}$ Ichiro MATSUO ${ }^{3}$ and Koki YOKOTSUKA ${ }^{2}$ \\ 'Asama Chemical Co., Ltd., 20-3, Nihonbashi-Kodenma-cho, Chuo-ku, Tokyo 103-0001, Japan \\ ${ }^{2}$ The Institute of Enology and Viticulture, Yamanashi University, Kofu, Yamanashi 400-0005, Japan \\ ${ }^{3}$ Meiji Institute of Health Science, 540 Naruda, Odawara 250-0862, Japan
}

Received September 28, 1999; Accepted January 18, 2000

\begin{abstract}
Antimicrobial substances were isolated from the $50 \%$ ethanol extract of paprika seeds by ODS open column chromatography and reverse phase HPLC. Ten compounds (1-10) which demonstrated antimicrobial activity against Saccharomyces cerevisiae $(\mathrm{MIC}=1.3-2.6 \mathrm{mg} / l)$ were isolated. The structure of the major compound, $4(\mathrm{MIC}=2.6 \mathrm{mg} / l)$,

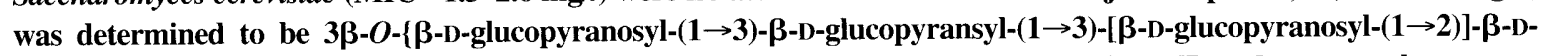
glucopyransyl-(1 $\rightarrow 4)$ - $\beta$-D-galactopyranosyl $\}-2 \alpha$-hydroxyl-(25R)-5 $\alpha$-spirostane by MS, NMR and sugar analyses.
\end{abstract}

Keywords: paprika seeds, antimicrobial substance, saponin, gitogenin

Paprika is a sweet or mildly pungent substance that belongs to the genus Capsicum. The brilliant red powder obtained from dried paprika fruits is used as a flavoring and garnish. We previously found that a water extract from paprika seeds exhibited strong antimicrobial activity towards yeasts (Yajima et al., 1996). The antimicrobial substance partially purified from paprika seeds was very stable at high temperatures, over a wide $\mathrm{pH}$ range. Furthermore, several application studies showed that this antimicrobial substance was a good food preservative to prevent yeast growth (Yajima et al., 1997; Yajima et al., 1998a; 1998b). However, this antimicrobial substance has not yet been completely purified, nor has its structure been elucidated. We report here the purification and structure of antimicrobial substances from paprika seeds.

To extract the antimicrobial substances, paprika seeds $(100 \mathrm{~g})$ were ground into a powder using a mechanical coffee grinder. The powder was mixed with $50 \%$ ethanol $(700 \mathrm{ml})$ and stirred at room temperature for $3 \mathrm{~h}$. The stirred solution was filtered through a cotton cloth and then centrifuged $(10,000 \times \mathrm{g}, 20 \mathrm{~min})$. The filtrate was concentrated to $1 / 2$ of its original volume by rotary evaporation at $40^{\circ} \mathrm{C}$ and then applied to a reverse phase open column $\left(16 \times 300 \mathrm{~mm}\right.$, Cosmosil $140 \mathrm{C}_{18}$-OPN, Nacalai Tesque) that had been equilibrated with $5 \%$ ethanol solution. After washing the column with $300 \mathrm{ml}$ of $5 \%$ ethanol solution, antimicrobial substances were eluted using a stepwise gradient of $20 \%$ to $80 \%$ ethanol. The fraction that eluted at $60 \%$ ethanol showed the highest antimicrobial activity. The antimicrobial activity against Saccharomyces cerevisiae W-3 was measured using a 96-well microplate (Yajima et al., 1996). The pre-culture of $S$. cerevisiae W-3 $(50 \mu \mathrm{l})$, a $50-\mu \mathrm{l}$ sample, and $150 \mu \mathrm{l}$ of YM medium were placed in each well of a 96-well microplate (U-bottom) and incubated at $25^{\circ} \mathrm{C}$ for $48 \mathrm{~h}$. The pre-culture was prepared by diluting (20-fold) the culture which had been incubated at $25^{\circ} \mathrm{C}$ for $24 \mathrm{~h}$. The minimum inhibitory concentration (MIC) was determined by visually monitoring the growth of W-3.

E-mail: yajima@asama-chemical.co.jp
The active fraction that eluted with $60 \%$ ethanol was concentrated by rotary evaporation at $40^{\circ} \mathrm{C}$ and then separated by reverse phase HPLC on a $\mu$ Bondasphere $C_{18}$ column $(19 \times 150$ $\mathrm{mm}$, Waters) using $50 \%$ ethanol as a eluent. Many peaks were detected by a RI detector (Hitachi L-3300). The compounds (110) obtained from ten peaks demonstrated the antimicrobial activity (MIC $=1.3-2.6 \mathrm{mg} / \mathrm{l}$ ) (Fig. 1).

Structure of the major compound, $4[\mathrm{MIC}=2.6 \mathrm{mg} / l$, yield $=$ $0.1 \%$ (based on weight of the starting seed sample)], was elucidated by MS, NMR and sugar analyses. The monosaccharide composition of compound $\mathbf{4}$ was analyzed by acid hydrolysis and HPLC analysis (Takayanagi et al., 1994). Compound 4 (1 $\mathrm{mg}$ ) was dissolved in $1 \mathrm{ml}$ of $2.5 \mathrm{M}$ trifluoroacetic acid and incubated for $5 \mathrm{~h}$ at $100^{\circ} \mathrm{C}$. Then the cooled trifluoroacetic acid solutions were evaporated by a centrifugal concentrator at $50^{\circ} \mathrm{C}$ just until the samples dried. The dry samples were injected onto an HPLC equipped with a CarboPac PA- 1 column $(4 \times 250 \mathrm{~mm}$, Dionex) and eluted with $15 \mathrm{~mm}$ sodium hydroxide. The eluted oligosaccharides were monitored using a pulsed amperometric detector (Hardy et al., 1988). Compound 4 had a sugar chain consisting of D-glucose (Glc) and D-galactose (Gal) in a proportion of $4.3: 1$ (Glc : Gal).

An aglycon of compound 4 was obtained according to the method of Lavaud et al. (1998). Compound 4 (10 mg) was dissolved in $1 \mathrm{ml}$ of a mixture containing $(1: 1) 6.5 \%$ aq. $\mathrm{HClO}_{4}$ and $0.02 \mathrm{~N} \mathrm{H}_{2} \mathrm{SO}_{4}$, and heated at $140^{\circ} \mathrm{C}$ for $2 \mathrm{~h}$. After cooling, the obtained aglycon precipitate was rinsed with $\mathrm{H}_{2} \mathrm{O}$ and dried in vacuo.

${ }^{1} \mathrm{H}$ - and ${ }^{13} \mathrm{C}$ - NMR spectra were recorded by a Varian Unity Inova 500 spectrometer at $500 \mathrm{MHz}\left({ }^{1} \mathrm{H}\right)$ and $125 \mathrm{MHz}\left({ }^{13} \mathrm{C}\right)$, and tetramethylsilane was used as an internal standard. Mass spectra, EI- and FAB-MS, were measured by a benchtop quadrupole mass spectrometer (JOEL) and a HITACHI M-80B mass spectrometer, respectively. The ${ }^{13} \mathrm{C}-\mathrm{NMR}$ data of the aglycon of compound $4\left([\mathrm{M}]^{+} \mathrm{m} / \mathrm{z} 432\right)$ agreed with those of (25R)-5 $\alpha$ -

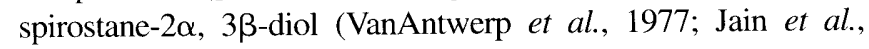
1987; Uniyal et al., 1991) (Table 1, Fig. 2). 


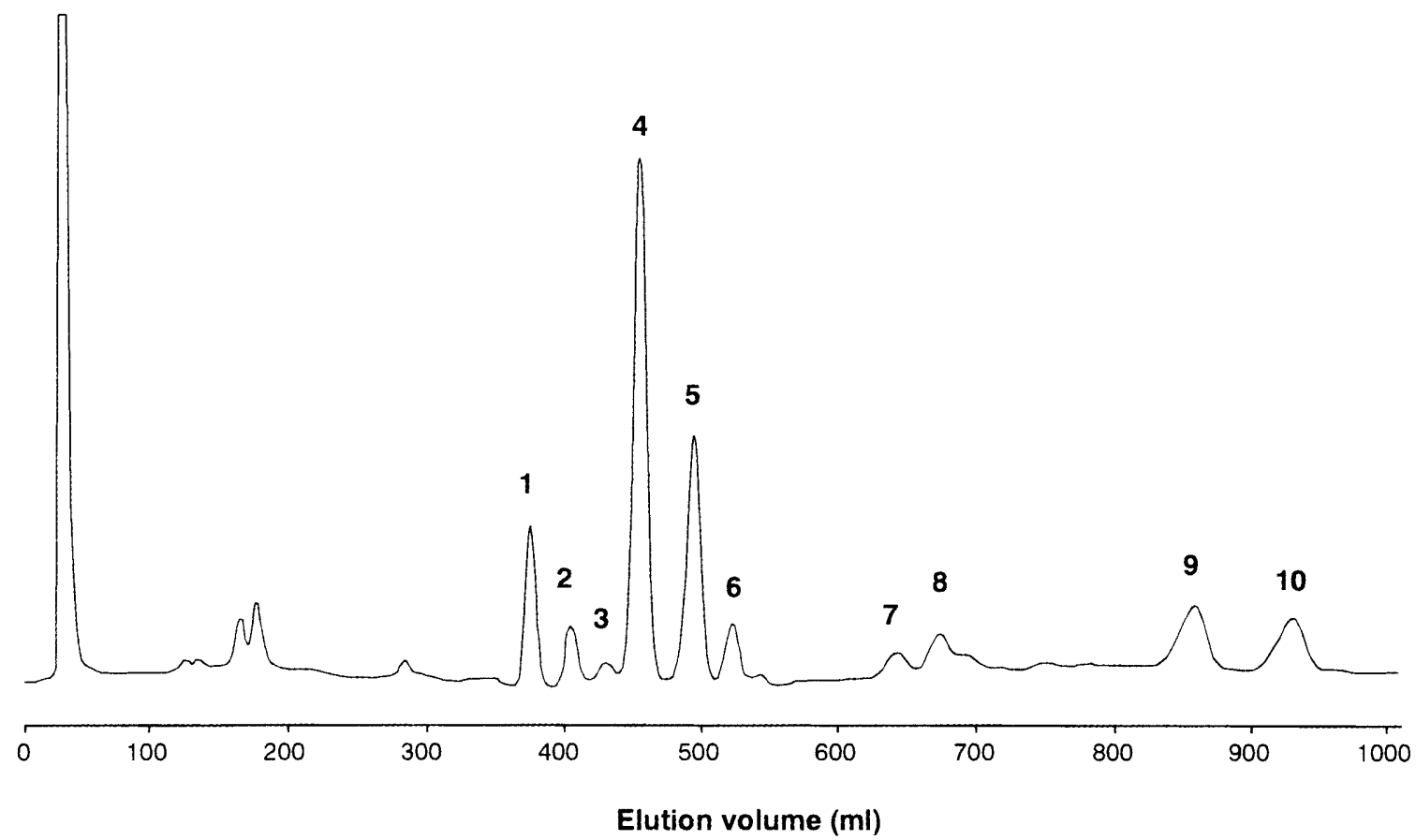

Fig. 1. HPLC chromatogram of the active fraction obtained from ODS open column chromatography. Active fraction eluted at $60 \%$ ethanol was separated by reverse phase HPLC on a $\mu$ Bondasphere $\mathrm{C}_{18}$ column $(19 \times 150 \mathrm{~mm}$, Waters) using $50 \%$ ethanol as the eluent. Eluted substances were detected by an RI detector (Hitachi L-3300).

Table 1. ${ }^{13} \mathrm{C}$ NMR chemical shifts for aglycon of compound 4 in $\mathrm{CDCl}_{3}(\delta$ values; $125 \mathrm{MHz}$ ).

\begin{tabular}{cccc}
\hline Position & $\delta(\mathrm{ppm})$ & Position & $\delta(\mathrm{ppm})$ \\
\hline 1 & 45.0 & 15 & 31.7 \\
2 & 73.1 & 16 & 80.8 \\
3 & 76.4 & 17 & 62.2 \\
4 & 35.6 & 18 & 16.5 \\
5 & 44.8 & 19 & 13.6 \\
6 & 27.8 & 20 & 41.6 \\
7 & 32.1 & 21 & 14.5 \\
8 & 34.4 & 22 & 109.2 \\
9 & 54.3 & 23 & 31.4 \\
10 & 37.6 & 24 & 28.8 \\
11 & 21.2 & 25 & 30.3 \\
12 & 40.0 & 26 & 66.8 \\
13 & 40.6 & 27 & 17.1 \\
14 & 56.1 & & \\
\hline
\end{tabular}

Compound 4 showed an $[\mathrm{M}-\mathrm{H}]^{-}$ion at $\mathrm{m} / \mathrm{z} 1241$ in the negative-ion FAB-MS data. The ${ }^{1} \mathrm{H}$ - NMR spectrum of this compound showed five sugar anomeric protons $[\delta 4.46(\mathrm{~d}, J=7.8$ $\mathrm{Hz}) ; 4.72(\mathrm{~d}, J=7.7 \mathrm{~Hz}) ; 4.87(\mathrm{~d}, J=7.9 \mathrm{~Hz}) ; 4.66(\mathrm{~d}, J=7.9$ $\mathrm{Hz}) ; 5.05(\mathrm{~d}, J=7.9 \mathrm{~Hz})]$. All the proton and carbon signals due to the sugar moiety of compound $\mathbf{4}$ were assigned according to ${ }^{1} \mathrm{H}-{ }^{-} \mathrm{H}$ COSY, TOCSY, and GHSQC experiments (Table 2). The HMBC spectra of the compound showed long-range correlation between 1'- $\mathrm{H}$ of galactose and $\mathrm{C}-3$ of the aglycon, indicating a glycosidic linkage of galactose to $\mathrm{C} 3-\mathrm{OH}$ of the aglycon (Fig 2). Other long-range correlations between $1^{\prime \prime}-\mathrm{H}$ of glucose and C-4' of galactose, $1^{\prime \prime \prime}-\mathrm{H}$ of glucose and C- $3^{\prime \prime}$ of glucose, $1^{\prime \prime \prime \prime}-\mathrm{H}$ of glucose and C- $3^{\prime \prime \prime}$ of glucose, and $1^{\prime \prime \prime \prime \prime}-\mathrm{H}$ of glucose and C-2" of glucose were also observed. The anomeric con-figurations of galactose and glucose were concluded to be all $\beta$ based on the large coupling constants $(J=7.7-7.9 \mathrm{~Hz})$. Thus, the structure of

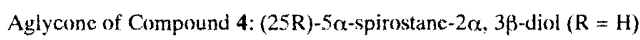

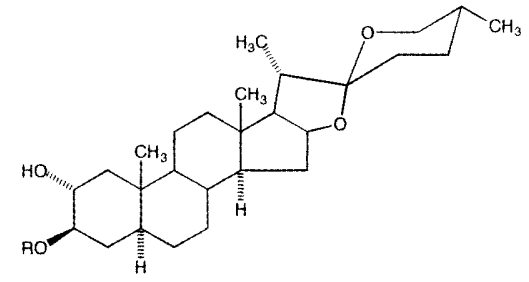

Compound $4 \mathrm{R}=$ sugar moicty: B-D-glucopyranosyl-(1 $\rightarrow 3)-$-B-D glucopyransyl- $(1 \rightarrow 3)-\mid B-D$-glucopyranosyl- $(1 \rightarrow 2) \mid-B$-D-glucopyransyl- $(1 \rightarrow 4)$ 63-D-galactopyranoside

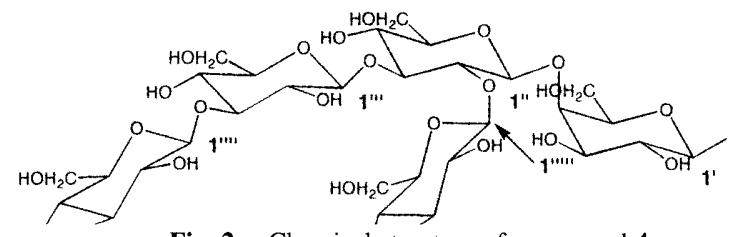

Fig. 2. Chemical structure of compound 4 .

the sugar moiety was determined to be $\beta$-D-glucopyranosyl$(1 \rightarrow 3)$ - $\beta$-D-glucopyransyl-( $1 \rightarrow 3)$-[ $\beta$-D-glucopyranosyl- $(1 \rightarrow 2)]$ $\beta$-D-glucopyransyl-( $1 \rightarrow 4)-\beta$-D-galactopyranoside (Fig. 2 ).

The structure of compound 4 was similar to the gitogenin oligoglycosides isolated from red peppers (Yahara et al., 1994). The biological activities of gitogenin, including inhibition of tumour promoters (Mimaki et al., 1996) and the hypocholesterol effect (Sauvaire et al., 1991) have previously been investigated, but their antimicrobial activity toward yeasts has not been reported. Thus, to the best of our knowledge, this is the first report of antimicrobial activity of a gitogenin glycoside isolated from paprika seeds. 
Table 2. ${ }^{1} \mathrm{H}$ and ${ }^{13} \mathrm{C}$ NMR chemical shifts for sugar moiety of compound 4 in $\mathrm{CD}_{3} \mathrm{OD}$ ( $\delta$ values; $125 \mathrm{MHz}$ ).

\begin{tabular}{ccr}
\hline \multicolumn{1}{c}{${ }^{1} \mathrm{H}$} & ${ }^{13} \mathrm{C}$ \\
\hline $\mathrm{Gal}$ & & \\
$1^{\prime}$ & $4.46(\mathrm{~d}, J=7.8)$ & 103.1 \\
$2^{\prime}$ & 3.79 & 73.2 \\
$3^{\prime}$ & 3.64 & 75.8 \\
$4^{\prime}$ & 4.14 & 80.2 \\
$\mathrm{Glc}$ & & \\
$1^{\prime \prime}$ & $4.72(\mathrm{~d}, J=7.7)$ & 104.7 \\
$2^{\prime \prime}$ & 3.85 & 81.3 \\
$3^{\prime \prime}$ & 3.89 & 87.9 \\
$4^{\prime \prime}$ & 3.45 & 71.4 \\
$\mathrm{Glc}$ & & \\
$1^{\prime \prime \prime}$ & $4.87(\mathrm{~d}, J=7.9)$ & 103.9 \\
$2^{\prime \prime \prime}$ & 3.58 & 75.0 \\
$3^{\prime \prime \prime}$ & 3.70 & 88.2 \\
$4^{\prime \prime \prime}$ & 3.51 & 70.4 \\
$\mathrm{Glc}$ & & \\
$1^{\prime \prime \prime \prime}$ & $4.66(\mathrm{~d}, J=7.9)$ & 105.4 \\
$2^{\prime \prime \prime \prime}$ & 3.38 & 75.7 \\
$3^{\prime \prime \prime \prime}$ & 3.47 & 71.9 \\
$4^{\prime \prime \prime \prime}$ & 3.45 & 70.9 \\
Glc & & 704.4 \\
$1^{\prime \prime \prime \prime \prime}$ & $5.05(\mathrm{~d}, J=7.9)$ & 78.0 \\
$2^{\prime \prime \prime \prime \prime}$ & 3.30 & 78.2 \\
$3^{\prime \prime \prime \prime \prime}$ & 3.44 & \\
$4^{\prime \prime \prime \prime \prime}$ & 3.45 & \\
\hline & & \\
\hline
\end{tabular}

\section{References}

Hardy, M.R., Townsend, R.R. and Lee, Y.C. (1988). Monosaccharide analysis of glycoconjugates by anion exchange chromatography with pulsed amperometric detection. Anal. Biochem., 170, 54-62.

Jain, D.C. (1987). Gitogenin-3-O- $\beta$-D-laminaribioside from the aerial part of Agave catntala. Phytochemistry, 26, 1789-1790.

Lavaud, C., Voutquenne, L., Massiot, G., Men-Olivier, L.L., Das, B.C., Laprévote, O., Serani, L., Delaude, C. and Becchi, M. (1998). Saponins from the stem bark of Filicium decipiens. Phytochemistry, 47, $441-449$.
Mimaki, Y., Kanmoto, T., Kuroda, M., Sashida, Y., Satomi, Y., Nishino, A. and Nishino, H. (1996). Steroidal saponins from Hosta longipes and their inhibitory activity on tumour promoter-induced phospholipid metabolism of HeLa cells. Phytochemistry, 42, 1065-1070.

Sauvaire, Y., Ribes, G., Baccou, J.C. and Loubatieeres-Mariani, M.M. (1991). Implication of steroid saponins and sapogenins in the hypocholesterolemic effect of fenugreek. Lipids, 26, 191-197.

Takayanagi, T., Kimura, A., Chiba, S. and Ajisaka, K. (1994). Novel structures of $N$-linked high-mannose type oligosaccharides containing $\alpha$-D-galactofuranosyl linkage in Aspergillus niger $\alpha$-D-glucosidase. Carbohydrate Res., 256, 149-158

Uniyal, G.C., Agrawal, P.K., Sati, O.P. and Thakur, R.S. (1991). Agavieside $\mathrm{C}$, a steroidal glycoside from Agave cantala. Phytochemistry, 30, 1336-1339.

VanAntwerp, C.L., Eggert, H., Meakins, G.D., Miners, J.O. and Djerassi, C. (1977). Additivity relationships in carbon-13 nuclear magnetic resonace spectra of dihydroxy steroids. J. Org. Chem., 42 , 789-793.

Yahara, S., Ura, T., Sakamoto, C. and Nohara, T. (1994). Steroidal glycosides from Capsicum annuum. Phytochemistry, 37, 831-835.

Yajima, M., Takayanagi, T., Nozaki, K. and Yokotsuka, K. (1996). Inhibitory effect of paprika seed extract on the growth of yeast. Food Sci. Technol. Int., 2, 234-238.

Yajima, M., Nozaki, K., Takayanagi, T. and Yokotsuka, K. (1997). An antimicrobial fraction from the residue obtained by supercritical carbon dioxide extraction of Capsicum spp. for use in food preservation. J. Antibact. Antifung. Agents, 25, 131-137 (in Japanese with English abstract).

Yajima, M., Otoguro, C., Matsudo, T., Okuda, T., Takayanagi, T. and Yokotsuka, K. (1998a). Inhibitory effect of paprika seed extract on the growth of film-forming yeasts isolated from wines. J. Brew. Soc. Jpn., 93, 671-676 (in Japanese with English abstract).

Yajima, M., Nozaki, K., Takayanagi, T., Otoguro, C. and Yokotsuka, K. (1998b). Growth inhibition of film-forming yeasts during production of Ume-Zuke (pickled Japanese apricots) by an antimicrobial fraction extracted from paprika seeds. Food Sci. Technol. Int. Tokyo, 4, 199-202. 